\title{
PSYCHE
}

$\begin{array}{lll}\text { Vol. } 72 \text { MARCH, I965 No. I } & \text { N }\end{array}$

\section{WILLIAM MORTON WHEELER MEMORIAL ISSUE}

March 19, I965, is the centennial of the birth of William Morton Wheeler, Professor of Entomology at Harvard University from I908-1937 and an active member of the Cambridge Entomological Club for that period. The Editorial Board of Psyche has designated the present number of the journal as the William Morton Wheeler Memorial Issue and has arranged to include in it articles on ants and other social or subsocial insects. No attempt has been made to obtain contributions by all of Professor Wheeler's former students; most of the papers published here were already in the editorial office before plans for the memorial issue were definitely made. Included are contributions by three generations of students whose interest in social insects can clearly be traced to Professor Wheeler. We are indebted to Professor W. L. Brown, Jr., of Cornell University for the use of the accompanying photograph, which was taken about five years after Professor Wheeler was appointed at Harvard University.

A biographical account of Professor Wheeler, with a complete list of his publications, was published in Psyche, Volume 44, No. 3., I937.

F. M. Carpenter, Editor 

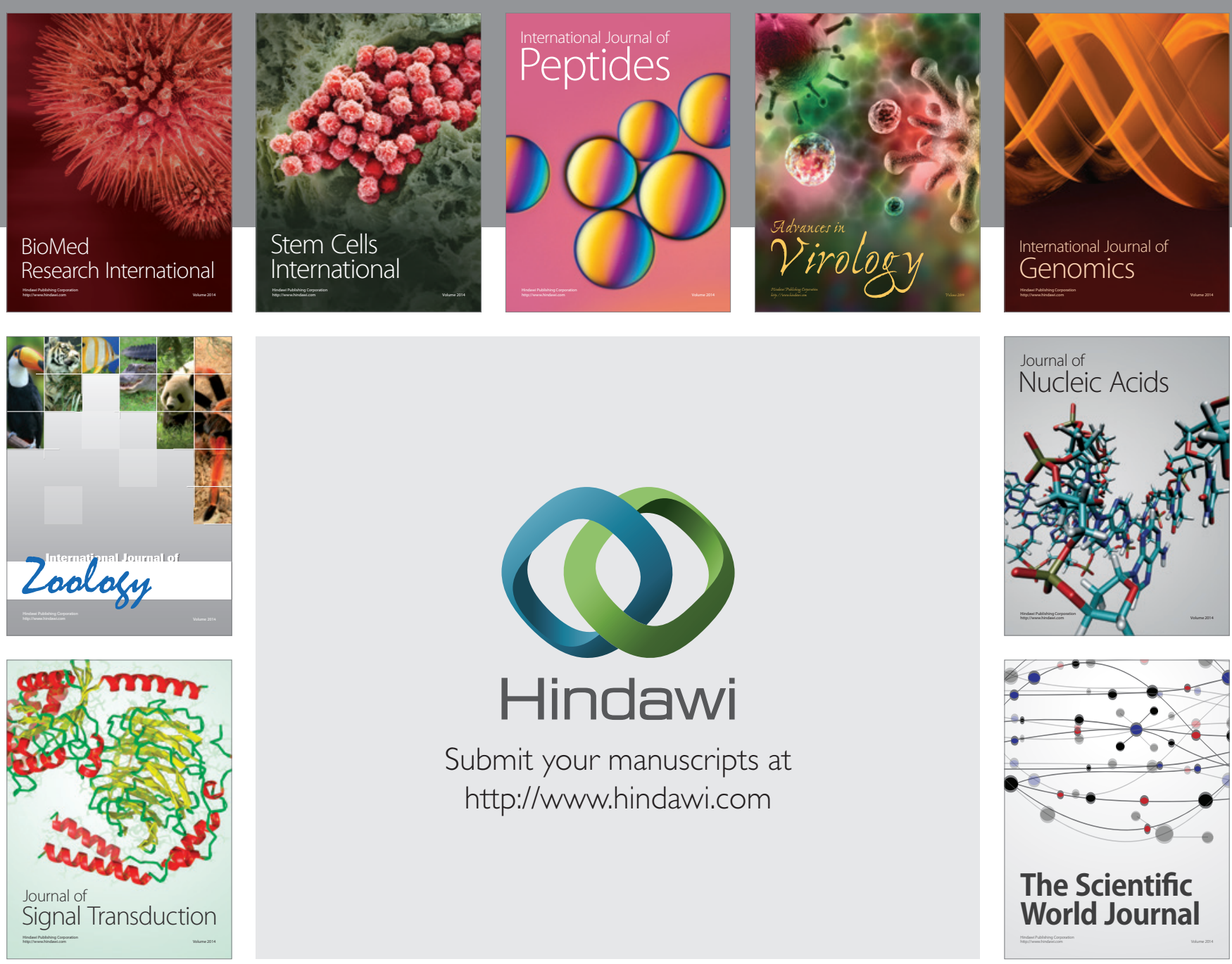

Submit your manuscripts at

http://www.hindawi.com
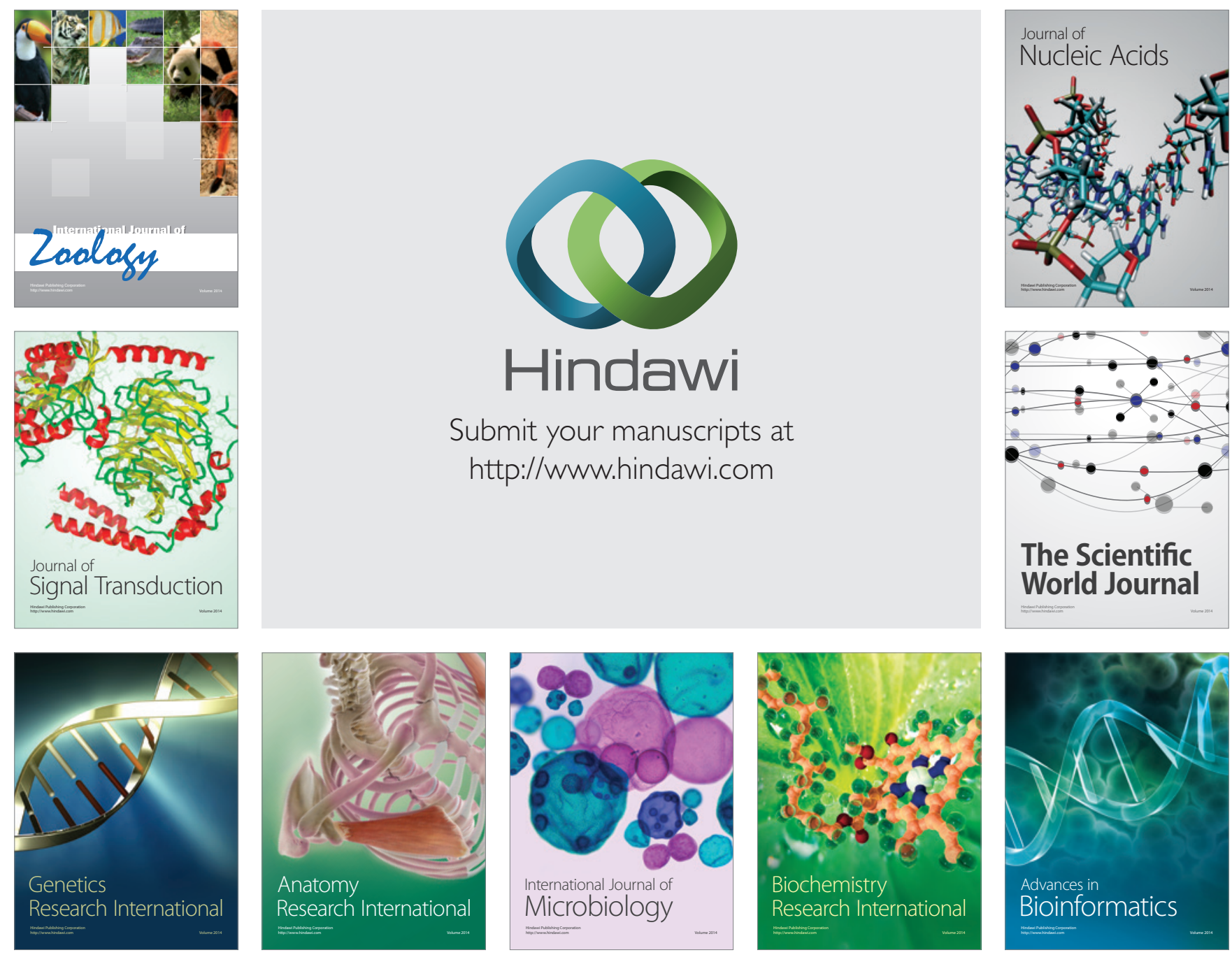

The Scientific World Journal
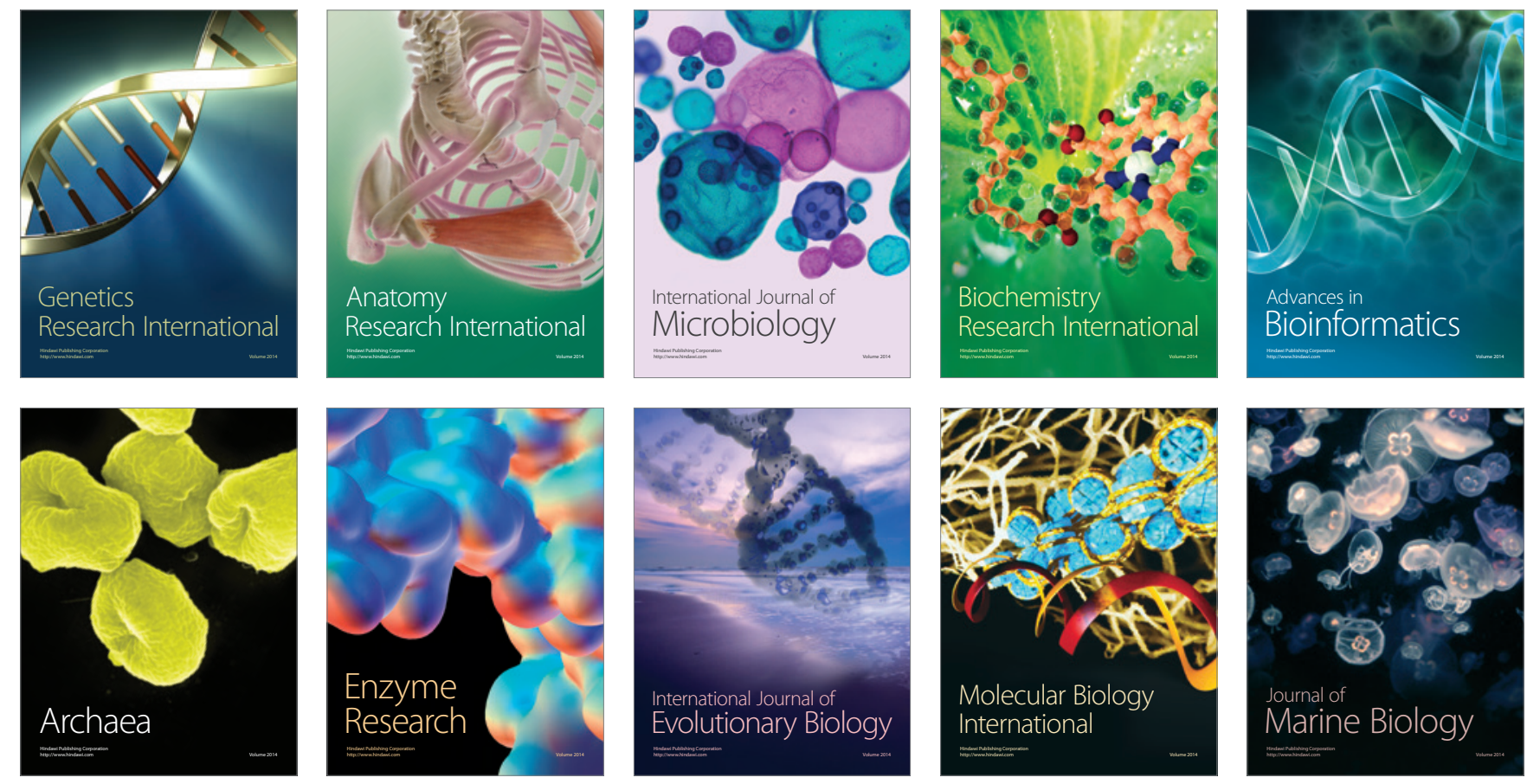